\title{
OBRAS DE FICCIÓN, FORMAS DE CONCIENCIA Y LITERATURA
}

\author{
Josep E. Corbî \\ Universitat de València \\ josep.corbi@uv.es
}

RESUMEN: Relatar lo ocurrido como invención: una introducción a la filosofía de la ficción contemporánea (2016a) ofrece al lector en castellano una magnífica oportunidad para familiarizarse con algunos aspectos centrales de la filosofía del lenguaje contemporánea y sus implicaciones para la teoría de la ficción. García-Carpintero recorre los argumentos fundamentales en favor y en contra de cada una de las posiciones relevantes, y nos propone finalmente un análisis alternativo de la norma de la ficción y una teoría neofregeana de los términos referenciales que logra esquivar algunas objeciones tradicionales. Esta discusión incluye, no obstante, dos objeciones a su norma de la ficción: una se refiere a las formas de la conciencia que esa norma presupone y la otra a la naturaleza del interés que suscitan los proyectos imaginativos vinculados a las obras de ficción.

PALABRAS CLAVE: aseveración, acto de habla, imaginación, referencia, metáfora

SUMMARY: Relatar lo ocurrido como invención: una introducción a la filosofía de la ficción contemporánea (2016a) offers to the Spanish reader an excellent opportunity to get in touch with central aspects in the current philosophy of language and their implications for fiction theory. In his book, García-Carpintero carefully presents the fundamental lines of argument for and against the most relevant views and, on this basis, defends his own analysis of the norm of fiction as well as a neo-Fregean theory of referential terms that averts some traditional objections. My review includes, however, two objections concerning García-Carpintero's norm of fiction, one relative to the forms of awareness that it seems to presuppose, and the other regarding the nature of the interest associated with the imaginative projects that are constitutive of fictional works.

KEY WORDS: assertion, speech act, imagination, reference, metaphor

\section{Preliminares}

En Relatar lo ocurrido como invención: una introducción a la filosofía de la ficción contemporánea (2016a), Manuel García-Carpintero nos invita a recorrer la filosofía del lenguaje contemporánea con el fin de analizar el modo en que las obras de ficción se relacionan con la realidad. El subtítulo nos advierte del carácter introductorio del texto, por lo que el autor se cuida de presentar ordenadamente cada una de las posiciones y argumentos en juego, de manera que el lector cultivado pueda confiar en que el texto no dará por supuestos conceptos y teorías que le resulten extraños. Este elemento formativo viene asociado, no obstante, a cierta dificultad del texto para quien no esté versado en los asuntos que en el mismo se tratan; sólo una lectura 
atenta, que se demore en los detalles y tome nota de las muchas anticipaciones que el autor realiza, le irá revelando la trama matizada de cuestiones que constituyen el debate filosófico contemporáneo en torno a la ficción. Parte de lo que podemos aprender en este proceso es a reconocer la forma propia del quehacer filosófico, pues el autor no se limita a dar cuenta del estado de la cuestión en los asuntos que examina, sino que su discurso, el texto que elabora, está impregnado de su propia posición filosófica. Relatar lo ocurrido como invención tiene, así, algo de la genealogía de la posición filosófica del autor al tiempo que constituye una invitación a que el lector, al recorrerla, elabore su propio punto de vista, pues sólo a través de ese esfuerzo creativo podrá alcanzar a comprender los hitos fundamentales del debate filosófico en torno a la ficción.

Qué entendemos por obra de ficción y de qué modo se distingue este tipo de obra de otras es un asunto fundamental en el libro. Se da por supuesto, con todo, que el lector tiene ya un acceso preteórico, intuitivo o experiencial a qué obras cumplen la condición de ser fictivas y cuáles no. Encontramos en el libro algunas observaciones generales al respecto, mas sólo a modo de recordatorio de lo que se supone compartido con el lector. Se nos advierte, por ejemplo, que: "en el sentido relevante, ficción y literatura no coinciden; hay ficción no literaria. Tampoco coinciden ficción y falsedad, ni ficción y uso no literal del lenguaje (metafórico, irónico, etc.)" (García-Carpintero 2016a, p. 47). Se insiste así en la necesidad de distinguir ficción de literatura y, de ese modo, se da a entender que las tesis que se defienden en el libro se refieren a toda obra de ficción, independientemente de cuál sea su condición literaria. No obstante, la mayoría de los ejemplos que sirven de apoyo a los argumentos de García-Carpintero remiten a personajes o situaciones extraídos de la literatura, entendida en un sentido amplio que incluye los filmes. No se discute en el libro si esta preferencia por presentar los argumentos mediante ejemplos literarios responde simplemente a un capricho del autor, de manera que cualesquiera otros ejemplos podrían haber cumplido esa misma función corroborativa o si, por el contrario, el uso recurrente de ejemplos literarios apunta a la idea de que los relatos literarios constituyen el caso paradigmático de ficción; pues, si así fuese, deberíamos entender qué hace que lo literario mantenga ese vínculo privilegiado con la ficción.

El enfoque general que García-Carpintero da a los ejemplos apunta a que su recurso a la literatura no responde más que a un motivo idiosincrático o, en todo caso, a alguna virtud argumentativamente subalterna como evocar en el lector las pasiones que la lectura de los 
textos literarios aludidos pudo provocarle en su momento, pero no responde a un motivo de mayor alcance filosófico, en relación con el modo en que los casos literarios ayudan a fundamentar las tesis que se defienden. Sólo una observación como la que sigue apunta en la dirección opuesta: "Nadie puede apreciar la ficción sin haber vivido la experiencia de 'estar inmerso' en una novela, una película, etc. Este 'estar inmerso' consiste fundamentalmente en una participación sentimental, emotiva" (García-Carpintero 2016a, p. 163). Se subraya así que la experiencia de "estar inmerso" es condición necesaria de nuestra capacidad de apreciar la ficción y, por tanto, de valorar su corrección y pertinencia. No sería de extrañar, sin embargo, que la capacidad de generar esa inmersión en el lector, de sumirlo en una ilusión estética, esté vinculada constitutivamente a ciertos rasgos de la estructura narrativa de un texto que acentúan su condición literaria. Es ésta una idea que elaboraré en la sección 5 y que afecta a la norma que García-Carpintero considera propia del acto de habla de hacer como que o fingir; defenderé, en concreto, que la neutralidad de esa norma respecto del interés literario o narrativo del proyecto imaginativo en el que esos actos nos embarcan no permite dar cuenta de la importancia de la experiencia de inmersión y, en definitiva, del modo en que distinguimos una obra de ficción de un ensayo o de un tratado de filosofía moral. Discutiré este punto así como la universalidad de las formas de conciencia que se presuponen en la norma de fingir que García-Carpintero nos propone, una vez que hayamos perfilado en las secciones 2 a 4 las tesis y los argumentos centrales de García-Carpintero en torno a la norma de fingir. Reservaré la sección 6 para presentar su análisis acerca del uso de los términos referenciales y de las metáforas en las obras de ficción.

\section{La norma de la aseveración y el acto de ficcionalizar}

En el capítulo 1, García-Carpintero se remonta a John Austin para introducir la distinción entre la fuerza ilocutiva y el contenido proposicional de un acto de habla, dado que un mismo contenido proposicional puede formar parte tanto de una promesa como de una aseveración, de un ruego o de una predicción. En general, los actos del habla tienen la forma $\mathbf{I}(p)$, donde $p$ alude a su contenido proposicional e "I" a su fuerza ilocutiva. Una cuestión en disputa es el modo en que ha de quedar determinada la fuerza ilocutiva de un acto de habla. García-Carpintero examina en este punto tanto las propuestas de origen griceano, que se centran en las intenciones comunicativas del hablante, como las estrategias institucionales o 
convencionales provenientes de Wittgenstein y del propio Austin. Si bien el concepto griceano de implicatura conversacional desempeña un papel relevante en el análisis de la ficción que García-Carpintero defiende, no por ello entiende que la perspectiva intencionalista nos ayuda a determinar los rasgos constitutivos de los distintos actos de habla. De hecho, García-Carpintero opta por un lectura normativa o institucional y, con ese propósito, se demora en el estudio de la norma constitutiva de la aseveración. Al respecto, García-Carpintero toma como punto de partida la norma del conocimiento que Timothy Williamson (1996) propone (C: aseverar $p$ es correcto si y sólo si uno sabe $p$ ), aunque entiende que $\mathrm{C}$ no es suficiente para dar cuenta de la naturaleza social de la aseveración y, por ello, elabora esta otra norma:

(La norma de la transmisión del conocimiento, TC) Aseverar $p$ es correcto si y sólo si uno pone a su audiencia de resultas de ello en posición de saber $p$. (García-Carpintero 2016a, p. 42)

TC parece gozar de todas las virtudes que Williamson atribuye a la norma del conocimiento y permite, además, distinguir las condiciones en que podemos presuponer $p$ de aquellas en que podemos aseverarlo, pues se sigue de TC que, cuando $p$ es un conocimiento compartido entre el hablante y el oyente, no podemos aseverarlo sino tan sólo presuponerlo; en cambio, $\mathrm{C}$ no puede dar cuenta de esa distinción. Conviene subrayar, por último, que TC establece condiciones necesarias y suficientes, pero sólo en la medida en que "correcto" se entienda como "correcto prima facie", pues queda abierta la posibilidad de que interfieran factores ajenos a la norma de la aseveración y que un acto de habla que cumpla las condiciones establecidas no sea correcto a fin de cuentas por razones morales o de cualquier otro tipo. García-Carpintero nos propone, al final del capítulo, que aceptemos TC como norma constitutiva de la aseveración con el fin de iniciar su reflexión en torno a la norma constitutiva del acto de habla de hacer como que o fingir, que es el que a su entender da lugar a las obras de ficción.

En el capítulo 2, comienza el estudio propiamente dicho del discurso de la ficción. El punto de partida es la propuesta de John Searle, quien entiende que en los relatos de ficción las palabras conservan su significado habitual, si bien quedan en suspenso las normas vinculadas a los actos de habla en las que aquéllas se utilizan; en este sentido, "el autor de una obra de ficción finge (no engañosamente) 
llevar a cabo una serie de actos de habla, normalmente de la clase aseverativa" (García-Carpintero 2016a, p. 48). Frente a ello, GarcíaCarpintero defenderá, de la mano de Kendall Walton (1990) y Gregory Currie (1990), que la creación de una ficción no requiere fingir que se realiza una serie de actos de habla, sino llevar a cabo un acto de habla específico, a saber, un acto de hacer como que o fingir. En cualquier caso, estos actos de habla se realizan al fingir que se llevan a cabo los actos del habla vinculados literalmente a las palabras que se utilizan. García-Carpintero entiende, siguiendo a Walton, que el acto de habla de fingir está asociado, en su esencia, a la capacidad de imaginar y, por otra parte, que imaginar es una actitud proposicional primitiva. Hacer como que o fingir constituye un caso de invocación de la imaginación en el que se requiere el uso de un atrezo como el que los niños emplean al jugar con montones de barro:

(1) Aquí hay tres pasteles

(2) He cocinado ese pastel

Podemos, entonces, introducir la fuerza ilocutiva "es fictivo que" $\left(\mathbf{F}_{j}\right)$ para dar cuenta de los actos de habla que realizan los niños en ese juego:

(3) $\mathbf{F}_{j}$ (aquí hay tres pasteles)

(4) $\mathbf{F}_{j}$ (he cocinado ese pastel)

Así pues, el juego de fingir da lugar a verdades fictivas como $\mathbf{F}_{j}$ (Pau ha pisado un pastel) y, por tanto, abre la puerta al error y a la ignorancia. Cuáles son los límites de las verdades fictivas relativas a una ficción es un asunto que discutiremos en la sección siguiente, pero parece claro que ha de comprender algo más que lo que se asevera explícitamente en ella, pues los actos de ficcionalizar -neologismo que acepta García-Carpintero con alguna reticenciano pueden ser literales, es decir, no hay ningún acto del habla cuya interpretación literal nos permita identificarlo como un acto de ficcionalizar. Es necesario, por tanto, que atendamos a las implicaturas conversacionales para determinar su sentido y, de ese modo, el análisis de Grice recupera parte del terreno que le había hecho perder el énfasis en la idea de norma.

\section{Mundos imposibles}

Si hasta ahora hemos estudiado la fuerza ilocutiva propia de la ficción, el capítulo 3 se adentra en el análisis del contenido proposicional 
del acto de ficcionalizar. Siguiendo a Walton, podemos decir que el contenido de un discurso fictivo puede expresarse mediante un conjunto de verdades parafictivas cuya forma es:

\section{(6) $\mathbf{F}_{j}(p)$}

Donde $\mathbf{F}$ quiere decir "es fictivo que", " $p$ " es el contenido proposicional que se considera fictivo y el subíndice $j$ alude a la obra de ficción de la que se afirma que $p$ es una verdad fictiva. Por supuesto, debemos distinguir las verdades parafictivas de las metafictivas, es decir, de las verdades sobre la obra de ficción de que se trate. La afirmación de que Don Quijote es un personaje de ficción es a todas luces una verdad metafictiva, pero no una verdad parafictiva, pues no es fictivo en El Quijote que Don Quijote sea un personaje de ficción. A la hora de especificar la norma que determina las verdades fictivas de una obra, García-Carpintero toma como punto de partida la propuesta de David Lewis en "Truth in Fiction" (1978), que responde a la idea de que lo que en nuestro mundo es ficción se afirma como un hecho conocido en ciertos mundos posibles. Cuáles sean esos mundos posibles es asunto que Lewis va perfilando con el fin de evitar una lectura demasiado restrictiva de las verdades fictivas o suponer un conocimiento exhaustivo del mundo real por parte del narrador y del lector. La primera dificultad se resuelve mediante el uso de los contrafácticos, que nos llevan más allá de lo que haya dicho explícitamente el narrador y la segunda apelando a un conjunto de creencias compartidas en una comunidad para definir el mundo respecto del cual se establece el contrafáctico. No me demoraré en los detalles de la propuesta de Lewis, cuyas variantes y argumentos García-Carpintero presenta con su habitual cuidado. Destacaré sólo tres aspectos que nos serán útiles para presentar y discutir en la sección siguiente la norma de las verdades fictivas con la que GarcíaCarpintero se compromete a fin de cuentas.

El primer aspecto es el carácter no reductivo del análisis de Lewis. No hay, en este sentido, afán alguno de explicar reductivamente la noción de verdad fictiva en términos de mundos posibles, pues, como subraya García-Carpintero, "nadie que no sepa ya distinguir verdades fictivas (directa o indirectamente generadas) de otro tipo de proposiciones va a aprender a hacerlo mediante la teoría de Lewis" (2016a, p. 70). Entiendo que el análisis normativo que García-Carpintero esboza está sujeto a esa misma restricción - aunque no sea éste un extremo que quede explícitamente confirmado en punto alguno-, pues nadie que no entendiese en qué consiste una ficción podría 
alcanzar esa comprensión a través de la norma que su teoría nos procura. Por ello, el modo en que entendamos, por ejemplo, el concurso de la imaginación en esa norma se basará en una comprensión previa del discurso de la ficción. La norma aspirará más bien a lograr una explicación que resulte iluminadora, de manera que nuestra comprensión de la noción de verdad fictiva mejore o se amplíe gracias a ella. Se sigue que la norma que García-Carpintero articule a fin de cuentas deberá no sólo ser adecuada por su capacidad de identificar una condición necesaria y suficiente de si $p$ es una verdad fictiva en una obra de ficción $O$, sino hacernos avanzar o profundizar en la comprensión de la noción de verdad fictiva.

El segundo punto que convendría destacar es que la noción de mundo posible se ha utilizado de manera estándar en la semántica contemporánea para dar cuenta de los condicionales contrafácticos. Se considera, en ese sentido, que un contrafáctico es verdadero si, en el mundo más cercano al mundo real en el que es verdadero su antecedente, también lo es su consecuente. Ahora bien, dado que el antecedente es falso en el mundo real, es razonable pensar que es imprescindible el concurso de la imaginación para determinar qué puede acontecer en el mundo más cercano a este en el que el antecedente es verdadero. Por otra parte, parece que en el razonamiento práctico recurrimos constantemente al uso de condicionales contrafácticos cuando valoramos los diferentes cursos de acción a nuestro alcance con el fin de tomar la decisión más apropiada. En tales casos tratamos de imaginarnos qué se seguiría de la verdad del antecedente; el único rasgo específico de estos contrafácticos estribaría en que consideramos que está en nuestras manos que su antecedente se cumpla. No parece, pues, que la invocación de la imaginación sea un atributo específico de las obras de ficción y, por tanto, la norma que determine las verdades fictivas deberá atender a esta circunstancia y determinar qué uso específico de la imaginación es propio de las mismas. No tengo la impresión, con todo, de que la norma que García-Carpintero nos propone - y que examinaremos después - atienda a esta exigencia, ni siquiera que pretenda conseguirlo.

El tercer aspecto se refiere a una de las dificultades más importantes con las que ha de lidiar el planteamiento de David Lewis y, en general, cualquier acercamiento a la noción de verdad fictiva en términos de mundos posibles. Cualquier contrafáctico con un antecedente imposible es, según Lewis, vacuamente verdadero. Se sigue que, en el caso de las ficciones que generen de manera más o menos sistemática proposiciones contradictorias (y, por tanto, imposibles), cualquier proposición sería una verdad fictiva porque el contrafáctico 
que, según la teoría de Lewis, determina su condición de tal sería trivialmente verdadero. Con el fin de salvar estas dificultades, Lewis propone dividir una obra de ficción en un conjunto de subhistorias relevantemente consistentes; no obstante, García-Carpintero entiende que, si bien esa estrategia puede servir en algunos casos, no resulta plausible en los casos en que, como en las novelas y los cuentos de Franz Kafka: "las proposiciones problemáticas son el núcleo de la historia, las proposiciones fictivas más importantes para apreciarla adecuadamente" (2016a, p. 83). En estas circunstancias, si tratásemos de articular esas proposiciones en un universo coherente, perderíamos gran parte de la capacidad de despertar nuestra imaginación que es propia de algunas de las obras de Kafka. Necesitamos, pues, articular una teoría de la verdad fictiva que tenga en consideración la posibilidad de que las inconsistencias constituyan un aspecto crucial de ciertas obras de ficción. Y en este punto parece que han de desempeñar un papel primordial las intenciones comunicativas del autor. ${ }^{l}$ Son sus intenciones comunicativas las que determinan, en primer lugar, que estamos ante una obra de ficción y, por tanto, ante un acto de habla en el que se aplican las normas que le son propias. En segundo lugar, son esas mismas intenciones las que nos ayudan a identificar el género al que pertenece determinada obra de ficción $\mathrm{y}$, por tanto, en qué medida es pertinente intentar resolver ciertas inconsistencias o si más bien son esenciales al género de que se trate. En cualquier caso, las intenciones comunicativas del autor no alcanzan a determinar el contenido mismo de la obra sin el concurso de las normas del acto de ficcionalizar y en esto se distingue la estrategia normativa de García-Carpintero de una propuesta intencionalista de inspiración griceana.

\section{La norma de la ficción}

En el capítulo 3, García-Carpintero se compromete con F como norma del acto de ficcionalizar, tras discutir varias propuestas alternativas, como la de Currie (1990):

F Ficcionalizar es correcto si y sólo si uno pone a la audiencia esperada en posición de imaginar $p$, y $p$ es merecedora de ser imaginada por tal audiencia. (2016a, p. 89)

${ }^{1}$ García-Carpintero se distancia de Currie (1990) al rechazar que sea necesario apelar a las intenciones de un autor implícito y considera que basta con atender a las intenciones comunicativas del autor de la ficción. Esta última es precisamente la posición que defiende Currie (2010). 
Esta norma nos permite determinar las verdades fictivas de una obra en los siguientes términos:

G-C Una oración de la forma $\mathbf{F}_{f}(p)$ es verdadera syss la corrección o incorrección de $f$ respecto a la norma $\mathrm{F}$ depende del interés de imaginar $p$ por parte de la audiencia esperada. (García-Carpintero 2016a, p. 91)

Es fácil ver que frente al planteamiento de Lewis en términos de mundos posibles, G-C puede dar cuenta del uso de lo onírico y lo imposible en las obras de Kafka, pues, aun cuando sus narraciones adopten un tono realista, el intento de determinar su contenido fictivo desde ese punto vista no permite captar el interés de su proyecto imaginativo. G-C nos invita, por tanto, a buscar una perspectiva más atractiva desde la que determinar su contenido fictivo; así pues, podemos alcanzar una mirada que nos acerca a lo onírico y nos lleva a entender "La condena" (Kafka 1972) como una presentación narrativa de:

las consecuencias emocionales [...] de una relación paterno-filial de un tipo particular, la que se da entre padres autoritarios, prepotentes, que buscan siempre prevalecer y afirmar su preponderancia, e hijos medrosos, asustadizos, dependientes, incapaces de "matar al padre" y asumir un papel autónomo en el mundo adulto. (García-Carpintero 2016a, p. 93)

G-C nos ayuda también a dar cuenta del papel que desempeña lo onírico en películas como Mulholland Drive (David Lynch 2001) o $81 / 2$ (Federico Fellini 1963), y en ese potencial explicativo reside parte de la fuerza iluminadora de la propuesta de García-Carpintero frente a los análisis de Lewis o de Currie.

Al final del capítulo 3, nos advierte García-Carpintero del carácter abstracto que tiene cualquier norma, incluida G-C, naturalmente. Cabe esperar, entonces, que la capacidad de esta última para dar cuenta de nuestras prácticas requiera que exista alguna forma de convención o acuerdo en torno a que ésa sea la norma que inspira nuestros juicios acerca del contenido de las obras de ficción. Este anclaje a nuestras prácticas subraya el carácter histórico de cualquier norma que quiera dar cuenta de las mismas y, por tanto, abre la posibilidad de introducir cambios en nuestras prácticas que den lugar a una norma ligeramente diferente, pero que guarde el suficiente grado 
de continuidad para reconocerlas como prácticas que comparten un aire de familia o, incluso, como la misma práctica identificada a partir de un entrelazamiento de rasgos relevantes. De todos modos, si concibiésemos así la práctica de ficcionalizar, tal vez perdería interés la tarea de determinar la norma que la rige en términos de condiciones necesarias y suficientes, pues difícilmente podría dar cuenta de las relaciones de continuidad entre diferentes prácticas a lo largo de la historia o entre las prácticas que se dan en grupos sociales o culturales diferentes o entre las diferentes manifestaciones de esa misma práctica en un mismo grupo (Friend 2008, 2011 y 2012).

La respuesta de García-Carpintero a estas inquietudes apunta en la dirección de la generalidad, pues considera que tanto aseverar como ficcionalizar son actos de habla universales, constitutivos de cualquier orden social reconociblemente humano, al menos si los caracterizamos con el suficiente grado de generalidad:

¿Qué alternativas existen para prácticas tales como aseverar, dar instrucciones, prometer? Descritas de una forma general, no parece que haya alternativas que permitan resolver los problemas de coordinación a que éstas sirven, tales como distribuir adecuadamente la información entre los interesados para un mejor funcionamiento social [...] Lo mismo se aplica a ficcionalizar y a los beneficios que proporciona la participación desde la más temprana infancia en prácticas colectivas de imaginar. (2016a, pp. 101-102; cfr. García-Carpintero 2013 y 2016b)

La universalidad del acto de ficcionalizar se reivindica por una función social que García-Carpintero no se atreve a caracterizar, pero que estima constitutiva de toda vida social. Esa universalidad no se extiende, con todo, a los diferentes géneros de ficción cuya variabilidad histórica se reconoce. Parece, entonces, que el análisis en términos de casos paradigmáticos y de aires de familia podría aplicarse sin temor al estudio de las normas que rigen los géneros y al modo en que estos últimos se interrelacionan y varían a lo largo de la historia. Las normas difícilmente identificarían en tal caso condiciones necesarias y suficientes, sino que más bien apuntarían a casos paradigmáticos y a un conjunto de rasgos que pueden legitimar nuestra identificación de las verdades fictivas de una obra desde la perspectiva de cierto género o por su afán de situarse entre varios géneros o de inaugurar un género relativamente nuevo. ${ }^{2}$ No veo por qué esa estrategia

${ }^{2}$ En Corbí 2012, caps. 4-5, introduzco el concepto de disciplina narrativa para dar cuenta del entramado de nociones que nos permite identificar una práctica 
explicativa no podría extenderse al acto de ficcionalizar, aunque se considerase universal, una vez que renunciamos a la posibilidad de ofrecer una explicación reductiva del mismo.

Hay, además, razones para dudar de la universalidad de G-C en cuanto norma que rija los modos en que nos involucramos en el discurso de la ficción. Para ello, trataré de mostrar, en primer lugar, que existen modos de relacionarnos con la ficción que no se atienen a G-C precisamente porque cuestionan uno de los supuestos en los que esa norma descansa. Mas, una vez que reconozcamos que G-C constituye como mucho uno de los modos de relacionarnos con la ficción, resultará poco plausible que ese modo de relación pueda entenderse como algo universal, pues los supuestos en que descansa G-C no parecen ser constitutivos de nuestra vida social.

Analicemos con este propósito una reflexión de Ulrich en El hombre sin atributos de Robert Musil acerca del papel del instinto teatral en el comportamiento de Su Excelencia, quien acaba de recibirlo en su palacio, y su relación con la costumbre de la clase media de acudir a los teatros para entretenerse por un precio módico:

Ulrich tuvo tiempo para tales reflexiones porque esperó un rato a que Su Excelencia hablase. El instinto teatral para el disfraz y la transformación, uno de los placeres de la vida, pudo verse aquí en toda su pureza, sin el menor rastro o conciencia de una actuación; se manifestó tan fuertemente en su arte inconsciente y eterno para la autorrepresentación que, en comparación, el hábito de la clase media de construir teatros y representar obras como un arte que puede alquilarse por horas le pareció bastante antinatural, decadente y esquizoide. (Musil 1995, p. 85; la traducción en todas las citas de esta obra es mía)

Como vemos, Ulrich sitúa en el ámbito de lo teatral tanto el comportamiento de Su Excelencia como la representación en un escenario, pues asocia ambas al gusto por la transformación y el disfraz. Entiende, sin embargo, que en el comportamiento de Su Excelencia no hay conciencia de estar actuando, mientras que en la escenificación de una obra tanto el actor como el espectador están divididos en dos formas de conciencia, una que atiende al contenido representado en el escenario y la otra a lo que acontece a su alrededor. No obstante, G-C parece estar comprometida con esta división entre dos formas de conciencia al subrayar la contraposición entre aseverar y ficcionalizar,

como moral. Tal vez esa noción pueda ser útil para analizar las relaciones entre los diferentes géneros narrativos y, en general, para identificar las prácticas asociadas a la idea de ficción. 
que parece asociada a su vez a la contraposición entre observar e imaginar y a la distinción entre lo que somos y lo que fingimos ser. Ulrich no considera, en cambio, que esa forma esquizoide de conciencia sea constitutiva de la experiencia teatral; de hecho, entiende que la conversación con Su Excelencia que seguidamente citamos, lo es también, aunque no esté sometida a la escisión propia del espectáculo con el que se entretienen las clases medias:

Y cuando Su Excelencia separó por fin los labios y le dijo: “Tu querido padre" sólo para detenerse, había algo en su voz que le hacía a uno notar sus manos amarillentas llamativamente bellas y algo como un aura en grácil sintonía con la moralidad que rodeaba toda su figura, que sedujo a Ulrich hasta olvidarse de sí mismo, como les ocurre a los intelectuales. Su Excelencia le preguntaba ahora qué es lo que hacía y cuando Ulrich dijo: "Matemáticas", respondió: "Por supuesto, qué interesante, ¿en qué escuela?" Cuando Ulrich le aseguró que nada tenía que ver con una escuela, Su Excelencia dijo: "Por supuesto, qué interesante, ya veo, investigación, universidad". Esto le pareció a Ulrich tan natural y preciso, justo como uno imagina una bella conversación, que sin darse cuenta se comportaba como si se sintiese en casa y siguiese sus propios pensamientos en vez de las exigencias del protocolo. (Musil 1995, p. 85) ${ }^{3}$

En la forma de teatralidad propia de esta conversación nos sentimos unificados con el protocolo de tal modo que nos parece que seguimos nuestros propios pensamientos y no ciertas exigencias externas. De nuevo, la idea de unidad de la conciencia surge como propia de una forma de teatralidad que aparece como superior, frente a la escisión que aflora por doquier en la vida burguesa y de la que Musil encuentra ejemplos no sólo en los teatros a los que acude la clase media, sino en el modo en que los miembros de esa clase participan en los servicios religiosos o en que los varones sanos entienden sus actividades sexuales:

\footnotetext{
${ }^{3}$ En El gatopardo (Luchino Visconti 1963) no parece que haya un adentro y un afuera del servicio religioso con el que se inicia la narración; no hay involucradas dos formas de conciencia. En El ángel exterminador (Luis Buñuel 1962) se muestra, en cambio, la incapacidad del burgués para alcanzar el modo de representación teatral de Su Excelencia. También es interesante, en este sentido, la contraposición entre The Remains of the Day (1986) y An Artist of the Floating World (1989) de Kazuo Ishiguro. En la primera novela, el mayordomo se refugia en una esfera privada de la que el protagonista de la segunda carece.
} 
"Cuánto más hermosa es ella al tornarse salvaje — pensó Ulrich — pero cuán mecánicamente acabó todo de nuevo." Verla lo había excitado, lo había incitado a hacerle el amor, pero ahora que ya estaba hecho sintió de nuevo lo poco que tenía que ver con él personalmente. Era simplemente una nueva y clara demostración de cómo un hombre sano puede tornarse en un lunático baboso a una velocidad increíble. Mas esta transformación erótica de la conciencia parecía tan sólo un caso particular de algo mucho más general porque una noche en el teatro, un concierto, un servicio religioso, son todos ellos manifestaciones de una vida interior similar, islas evanescentes de un segundo estado de conciencia que se interpola de vez en cuando en su estado ordinario. (Musil 1995, p. 119)

Si Ulrich estuviese en lo cierto al caracterizar la conciencia burguesa de este modo escindido o esquizoide y si concediésemos que el arte de Su Excelencia es también teatral sin que medie tal escisión, entonces deberíamos reconocer que G-C atiende tan sólo a la forma de teatralización propia de la clase media que acude a los teatros, a las iglesias o a sus citas sexuales, pero no daría cuenta de otros modos de teatralización que estarían sujetos a normas o criterios distintos. En tal caso, G-C no podría defenderse ya como condición necesaria de la teatralización ni, por tanto, de la ficción, pero, además, será difícil defenderla como condición universal, es decir, como algo más que un modo determinado a lo largo de la historia de relacionarnos con la ficción.

El argumento en defensa de la universalidad del acto de ficcionalizar que García-Carpintero nos ofrece depende crucialmente de la posibilidad de identificar una función social específica e imprescindible que no puede cubrirse más que a través de ese acto de habla. Se trata, por tanto, de articular una genealogía del acto de ficcionalizar similar a la que otros han elaborado para la aseveración o el conocimiento (Craig 1999; Williams 2002). Sin embargo, en la medida en que sospechemos que la conciencia escindida es una forma de la subjetividad propia del modo de vida burgués y que otros modos de vida incorporan los recursos de la ficción en formas de conciencia más unitarias, difícilmente podremos identificar una necesidad $N$ que sólo un acto de habla regido por G-C pueda cubrir; como mucho, podremos mostrar que $N$ sólo puede atenderse con G-C en un contexto dado, a saber, el modo de vida burgués. Parece constitutivo de una sociedad articulada en torno a una forma de conciencia más unitaria que $N$ se satisfaga por otros medios; por ejemplo, como lo hace $\mathrm{Su}$ Excelencia. 


\section{Ficción, contrafácticos y razonamiento práctico}

La segunda cuestión que me preocupa respecto de G-C es si los razonamientos prácticos han de entenderse como ficciones, pues parecen cumplir los requisitos que esa norma impone, dado que tales razonamientos involucran, como hemos visto, el estudio o examen de condicionales contrafácticos y, por tanto, (a) ponen a la audiencia en condiciones de imaginar cierto contenido y (b) ese contenido parece merecedor de ser imaginado por motivos prácticos. Si esto fuese así, debemos reconocer que al aseverar un contrafáctico (sea éste práctico o no) ficcionalizamos y, por tanto, que aseverar y ficcionalizar constituyen actos de habla que responden a normas diferentes pero compatibles, de manera que un mismo acto de habla podría responder a ambas normas. Ésta es una tesis que García-Carpintero defiende explícitamente en otros lugares:

Uno y el mismo acto podría realizarse con la intención de que esté sujeto a diferentes normas, y no sólo relativo a audiencias diferentes [...]. Así, según un tratamiento natural de los actos de habla indirectos, al emitir "No volveré a beber"/"Limpiarás las letrinas" uno asevera ("tácticamente", según la iluminadora metáfora de Dummett) que no volverá a beber/que tú limpiarás las letrinas, y ("estratégicamente", por seguir la metáfora) promete no volver a beber/ordena al interlocutor que limpie las letrinas. (2013, p. 356)

En Relatar lo ocurrido como invención, García-Carpintero da a entender en algún punto, no sólo que un acto de habla concreto puede responder tanto a la norma de la aseveración como a la de ficcionalizar, sino que un proyecto imaginativo completo podría responder a ambas normas:

Pese a que ficción o no ficción son ilocutivamente dispares (en mi propuesta, las primeras están sujetas a las normas de suscitar una rica actividad imaginativa; las segundas, a las normas de la verdad o a normas epistémicamente relacionadas), nada se opone a que una ficción pueda también ofrecer contenidos sujetos a esas normas. El interés de muchos de nuestros proyectos imaginativos así lo muestra. Ante la toma de una decisión difícil, tratamos de imaginarnos cómo sería nuestra vida en cada una de las opciones. (2016a, p. 184; cfr. García-Carpintero 2016b, pp. 128-130)

Parece, pues, que el interés de un proyecto imaginativo vinculado a la idea de ficción puede ser práctico y, por ello, puede estar asociado a la verdad de ciertos contrafácticos. Esta línea argumentativa 
nos obligaría, con todo, a reconocer como obras de ficción Ética a Nicómaco de Aristóteles y Fundamentación de la metafísica de las costumbres de Kant. No me parece que esta pueda ser una conclusión razonable. La entiendo más bien como una reducción al absurdo de G-C y, en concreto, como una invitación a determinar la naturaleza específica del interés que puede despertar un proyecto imaginativo para que pueda reconocerse como obra de ficción y que no podría ser, en ningún caso, un interés meramente moral o práctico. De hecho, podemos encontrar en Relatar lo ocurrido como invención algunas observaciones que apuntan en esta dirección y que asociaré a la idea de narratividad que propone Currie (2010). ${ }^{4}$

García-Carpintero insiste en que la experiencia de inmersión en la obra de ficción es una condición necesaria para nuestra comprensión de la norma de la ficción y está asociada a la función social que nos permite reivindicar la universalidad del acto de ficcionalizar. Sin embargo, no parece que la inmersión de la que hablamos sea compatible genuinamente con una preocupación por la verdad de los contrafácticos que se consideren en cada caso, como ocurre con un proyecto imaginativo vinculado a un razonamiento práctico. Puede que el autor de una obra de ficción esté de algún modo guiado por su compromiso con la verdad, pero no parece que el lector pueda estar constreñido también por ella, al menos no en los casos primigenios a los que alude García-Carpintero para dar cuenta de nuestra experiencia preteórica de la ficción. Esa asimetría respecto de la atención a la verdad por parte del autor y del lector no se da, en cambio, en el razonamiento práctico.

Con el fin de atender a esa asimetría, G-C debería indicar que el tipo de interés que despierta el proyecto imaginativo propio de la ficción no puede ser un interés cualquiera, sino un interés específico vinculado a esa experiencia de inmersión o de ilusión estética por parte del lector o del espectador. Esa vinculación no tiene por qué

\footnotetext{
${ }^{4}$ García-Carpintero parece reconocer la especificidad del interés de los proyectos imaginativos propios de las obras de ficción en el siguiente texto: "Mi propuesta es que una ficción con el contenido $p$ es el resultado de un acto que es correcto sólo si ofrece a las audiencias relevantes (audiencias del tipo pretendido, con el deseo de que se involucren en tales trabajos) una razón para imaginar $p$. Las razones en cuestión tienen que ver con lo que hace que merezca la pena que nos involucremos en las buenas ficciones; digamos, la sucesión de emociones que provoca el involucrarse en una novela de intriga bien trabada para quienes disfrutan de ese tipo de cosas" (García-Carpintero 2016b, p. 126). El autor no parece percibir, con todo, la existencia de una tensión entre esa apelación al tipo de interés propio de las buenas ficciones y la presunta neutralidad de la norma respecto de la naturaleza del interés que pueda tener un proyecto imaginativo.
} 
ser directa o inmediata, puesto que el lector o el espectador son capaces de distanciarse de la ilusión y puesto que, incluso, algunas obras los obligan a ello, pero García-Carpintero está obligado a reconocer que ha de quedar un rastro de esa experiencia, pues atribuye a la inmersión un papel primordial en nuestra compresión del acto de ficcionalizar. Como subraya Currie, ese rastro podría estar asociado a ciertos rasgos narrativos y, en tal caso, el acto de ficcionalizar dependería de una forma particular de invocar un proyecto imaginativo asociado a la forma literaria de un relato y, en general, a su narratividad. ${ }^{5}$ Una vez que detallemos el tipo de interés que es propio del acto de ficcionalizar en estos términos u otros similares, podremos ver por qué las obras de Aristóteles o de Kant aludidas párrafos antes no son obras de ficción en la medida en que su interés no está debidamente asociado a sus recursos narrativos.

Sin embargo, el énfasis en la narratividad nos obliga a revisar algunas otras afirmaciones o tesis que se defienden en el libro. La primera ya la hemos indicado, a saber, que, una vez que hayamos perfilado debidamente el interés de que se trata, G-C no podrá ser compatible con cierta forma de compromiso con la verdad por parte del lector. En segundo lugar, la distinción entre ficción y literatura que se subrayó al inicio quedaría desdibujada, pues el carácter literario de un texto sería constitutivo de su condición de obra de ficción. La tercera tiene que ver con el hecho de que el aprendizaje del lector sea meramente proposicional. Es cierto que el lector puede alcanzar formas de conocimiento que admitan una expresión proposicional como la que se indica en la última página del libro respecto de Fatal Attraction (Adrian Lyne 1987) y L'Amour l'après-midi (Eric Rohmer 1972), a saber, que "el adulterio es algo mucho menos moralmente liviano de lo que las actitudes morales generalizadas después de los sesenta nos pueden hacer pensar" (García-Carpintero 2016a, p. 188; las cursivas son del autor). Sin embargo, como subraya García-Carpintero, existen diferencias en cuanto al grado de sutileza en el tratamiento de esa idea en ambos filmes. La cuestión que me interesa es si esa sutileza

${ }^{5}$ No podemos demorarnos en el concepto de narratividad que Currie propone. Baste aludir al modo en que distingue las narraciones de otras representaciones, de manera que determinado texto tendría un grado mayor o menor de narratividad en función de su relación con los rasgos propios de las primeras: "Las narraciones, para resumir la propuesta, se distinguen de otras representaciones por lo que representan: relaciones sostenidas de naturaleza temporal y causal entre particulares, especialmente entre agentes. Otros tipos de discursos se centran en las causas: las teorías científicas, por ejemplo. Pero las teorías subrayan la generalidad, el carácter nomológico y la abstracción, mientras que las narraciones se centran en lo particular, lo contingente, lo concreto" (Currie 2010, pp. 27-28). 
— que podemos asociar a la idea de narratividad mencionada párrafos antes - afecta no sólo al proceso por el que llegamos a la conclusión sino al grado en que la comprendemos y, por ello, al modo en que altera nuestra visión del mundo e inspira nuestra actitud ante las más variadas situaciones. ${ }^{6} \mathrm{Si}$ la respuesta a esta pregunta fuese afirmativa, entonces la comprensión que alcanzamos no podrá ser meramente proposicional, sino también vivencial y práctica, en contra de lo que García-Carpintero parece afirmar. Y para alcanzar esa comprensión parece seguirse que el lector o el espectador han de dejarse llevar por un interés que no es práctico sino específico de la ficción. La cuarta tesis que convendría revisar o matizar se refiere a la respuesta de García-Carpintero a la pregunta: “¿Cómo puede atemorizarnos, enorgullecernos o producirnos curiosidad lo que sabemos que existe sólo "en la imaginación'?" (2016a, p. 164). En su respuesta, GarcíaCarpintero alude al hecho que resalta Walton de que el atrezo de una obra de ficción incluye también ciertos sucesos en el espectador y por ello entiende que:

Es un hecho sobre la psicología humana que esos sucesos pueden incluir no sólo las sensaciones visuales que experimentamos al leer la obra, sino otras tales como las cualidades conscientes asociadas a las emociones ficticias que venimos considerando. (2016a, p. 167)

De este modo, se presenta como un hecho accidental o contingente respecto de la obra de ficción el que formen parte de su atrezo las emociones ficticias que se despiertan en el lector. No se especifica en qué sentido son ficticias esas emociones, pero tal vez lo sean simplemente en el sentido de que forman parte del atrezo de una obra de ficción. Lo que quisiera destacar es que si el análisis del interés que sea pertinente especificar en G-C ha de estar vinculado a la idea de inmersión o de ilusión estética, entonces esas emociones difícilmente podrían mantener una mera relación contingente con la norma de ficcionalizar, pues parecen ser constitutivas del tipo de

${ }^{6}$ Ésta es, por ejemplo, la propuesta de Martha Nussbaum: “¿Cómo hay que escribir, qué palabras, qué formas, estructuras y organización hay que elegir, si estamos tratando de entender (lo que quiere decir, si somos, en ese sentido, filósofos)? A veces ésta se toma como una pregunta trivial y poco interesante. Defenderé que no lo es. El estilo tiene sus propias exigencias, expresa su propio sentido del asunto. La forma literaria no es separable del contenido filosófico, sino que ella misma forma parte del contenido - una parte integral, por tanto, de la búsqueda y de la enunciación de la verdad-" (1992, pp. 3-4; la traducción es mía). 
interés que el proyecto imaginativo debería despertar para que el acto de ficcionalizar fuese correcto.

\section{Los términos referenciales en las obras de ficción}

Las observaciones críticas de la sección anterior en nada afectan a la línea argumentativa del capítulo 4 en torno a las dificultades en el uso de términos referenciales, ya sean nombres propios o expresiones indéxicas, en las obras de ficción. La primera de las secciones se dedica a la presentación pormenorizada del debate entre las teorías fregeanas y millianas de los nombres propios en el uso ordinario del lenguaje. García-Carpintero reconstruye con cuidado los tres argumentos que condujeron a Frege a atribuir a los nombres propios no sólo una referencia sino también un sentido, a saber, (1) el argumento de la diferencia cognitiva entre "Héspero es Héspero" y "Héspero es Fósforo", a pesar de que "Héspero" y "Fósforo" se refieran al mismo planeta; (2) el argumento que se basa en la existencia de términos sin referente y, por último, (3) el argumento del discurso indirecto. La tesis descriptivista de Frege queda finalmente formulada como sigue:

DES Para cada nombre propio del lenguaje común $N$, existe una descripción el $D_{n}$ tal que: (i) todo usuario competente de $N$ debe asociarlo, en virtud de su competencia lingüística, con el $D_{n}$ y (ii) si $N$ tiene un referente $\mathbf{o}$, hay exactamente un $D_{n}$ y $\mathbf{o}$ es $D_{n}$. (2016a, p. 113)

Por supuesto, García-Carpintero recoge con el mismo esmero los argumentos de Kripke en contra de DES que le condujeron a defender la teoría del bautismo inicial como mecanismo para fijar la referencia de los nombres propios y, en definitiva, motivaron su tratamiento como designadores rígidos.

García-Carpintero reconoce la fuerza de los argumentos de Kripke en contra de DES, aunque nos recuerda que una teoría satisfactoria de los nombres propios no puede contentarse con objetar a DES, sino que ha de ser capaz de responder los argumentos de Frege en favor de la tesis descriptivista. La propuesta de García-Carpintero trata de ofrecer una caracterización de las expresiones referenciales que, a la luz de los argumentos de Kripke, reconozca que las descripciones y los términos referenciales tienen un comportamiento dispar, sin que por ello se excluya que una descripción pueda estar asociada semánticamente a un término referencial. Para ello, García-Carpintero 
distingue el acto de presuponer del de aseverar. El acto de presuponer es relativo a un contexto entendido, siguiendo a Robert Stalnaker (2002), como "un conjunto de proposiciones, que constituyen conocimiento o en algunos casos sólo conocimiento presunto (meras creencias) recíprocamente compartido por los participantes en los actos de significación" (García-Carpintero 2016a, p. 124; las cursivas son del autor). Presuponer consiste, en ese sentido, en poner de relieve una proposición que ya es parte del contexto. El contexto va cambiando según se habla, pues cualquier aseveración que no se cuestione queda inmediatamente incorporada al mismo. García-Carpintero defiende precisamente que "los elementos descriptivos [de los indéxicos] son parte de una proposición presupuesta, pero no son parte de la proposición aseverada" (2016a, p. 128). Y entiende que esta idea es cierta también de los nombres propios. La tesis descriptivista matizada así no es presa fácil de las objeciones de Kripke y, sin embargo, permite atender a los tres argumentos que motivaron a Frege a defender que los nombres propios tienen tanto una referencia como un sentido. Se trata ahora de aplicar esa teoría de los términos referenciales a su uso en las obras de ficción.

Las teorías millianas tienen dificultades para dar cuenta del uso de los términos referenciales en las obras de ficción porque éstos carecen de referente. Es cierto que se pueden postular formas de quasiintencionalidad, pero esta maniobra resulta excesivamente ad hoc y, por tanto, poco iluminadora. García-Carpintero entiende, en cambio, que la versión afinada de la teoría descriptivista que defiende puede dar cuenta del uso de los términos referenciales en las obras de ficción, distinguiendo entre las presuposiciones reales, vinculadas al atrezo con que se elabora la ficción, y las presuposiciones fingidas, generadas por las verdades fictivas que constituyen el contenido de una obra de ficción. Las presuposiciones referenciales asociadas al uso de términos referenciales dentro de la ficción son presuposiciones fingidas y tales términos funcionan como descripciones encubiertas, que incorporan tanto las descripciones asociadas, por ejemplo, a "Don Quijote" como las presuposiciones fingidas vinculadas a ese mismo personaje. A fin de cuentas, García-Carpintero defenderá que, al igual que podemos comprometernos con la existencia de entidades teóricas como los números y los conjuntos, podemos también comprometernos con la existencia de entidades ficticias como Don Quijote, aunque afirma que nuestro compromiso es más bien metafórico.

En el capítulo 5, García-Carpintero aprovecha algunos de los recursos que introdujo antes para presentar su teoría de la metáfora y su relación con la ficción. Se distancia de quienes, como Watson, 
insisten en que las intenciones comunicativas del hablante son irrelevantes a la hora de determinar los significados metafóricos, pues no permiten distinguir entre significar y querer decir. Por el contrario, entiende que el concepto griceano de implicatura conversacional es crucial a la hora de distanciarse del sentido literal de lo aseverado cuando éste es absurdo a todas luces y fundamental para entender, por tanto, que el hablante ha querido decir otra cosa. No obstante, es imprescindible determinar el modo particular en que operan las implicaturas conversacionales en el caso del uso metafórico del lenguaje y, para ello, García-Carpintero recurre a la enumeración de un conjunto de normas que atienden sobre todo a la traslación de ciertas propiedades o rasgos de un dominio fuente a un dominio objetivo. Una consecuencia relevante de esas normas es que permiten distinguir entre verdad y falsedad metafórica, así como reconocer que "las buenas metáforas 'son abiertas': las propiedades transferidas no se agotan en ningún conjunto dado que el crítico pueda mencionar" (2016a, p. 162). En ese contexto, el autor entiende que el compromiso con los personajes de ficción tiene que ver con un uso metafórico del aparato referencial del lenguaje del que forman parte el signo de identidad y los cuantificadores.

El capítulo 5 concluye con una breve reflexión acerca de las ficciones no literarias, como las ficciones pictóricas y musicales. Respecto de las ficciones pictóricas, distingue entre pinturas realistas y abstractas. En cuanto a las primeras, entiende que una vez que dispongamos de una teoría de lo específico en una representación pictórica, no nos resultará difícil determinar qué verdades son fictivas en determinado cuadro. Su análisis de la representación pictórica nos remite a la idea de "ver $A$ como $B$ " (Wollheim 1980, Peacocke 1987) y, en cualquier caso, se distancia de la idea de Watson de que toda representación pictórica ha de entenderse por su capacidad para generar verdades fictivas visuales, pues excluye la pictoricidad no fictiva. En la pintura abstracta, las verdades fictivas visuales quedan reducidas a ciertas sensaciones visuales y, en el caso de la música, las verdades fictivas directas tendrán que ver con las relaciones estructurales entre los sonidos emitidos. Puede decirse en un sentido metafórico que la música expresa ciertas emociones, humores y sentimientos, pero podría considerarse una verdad fictiva el que un sujeto también fictivo se vea afectado por ciertos estados emotivos y, de ese modo, la música tendría un cierto componente narrativo. 


\section{Conclusión}

Como hemos visto, Relatar lo ocurrido como invención ofrece al lector en castellano una magnífica oportunidad para familiarizarse con algunos aspectos centrales de la filosofía del lenguaje contemporánea y sus implicaciones en la teoría de la ficción. Por supuesto, un análisis de la fuerza ilocutiva y del contenido proposicional de los actos del habla que no sólo dé cuenta del uso del lenguaje en los contextos prácticos u ordinarios, sino también de su uso en las obras de ficción, quedará reforzado frente a un análisis alternativo que fracasase en este último empeño. García-Carpintero recorre con esmero admirable los argumentos fundamentales en favor y en contra de cada una de las posiciones relevantes, y nos propone al final un análisis de la norma de la ficción y una teoría neofregeana de los términos referenciales que logra esquivar alguno de los escollos tradicionales en este camino.

La destreza de García-Carpintero en la construcción de los argumentos pone al lector en condiciones de ponderar y cuestionar las propuestas y razones que se le ofrecen, incluida la que el propio autor defiende. Es ésta una virtud que el libro cultiva con primor exquisito y que me ha incitado a dejar constancia de algunas inquietudes y perplejidades que me ha suscitado la norma de la ficción que García-Carpintero elabora tan cuidadosamente. He defendido, en primer lugar, que el modo en que concibe la norma del acto de ficcionalizar, es decir, como una norma contrapuesta a la del acto de aseverar (mas no incompatible con ella), parece presuponer la escisión en dos formas de conciencia que, a mi entender, difícilmente puede concebirse como elemento constitutivo de la ficción, tal y como sugiere la experiencia de la conversación entre Ulrich y Su Excelencia. He insistido, en segundo lugar, en que la norma de ficcionalizar debe especificar el tipo de interés que despierta el proyecto imaginativo si hemos de aceptar que, como da a entender García-Carpintero, la experiencia de inmersión en la ficción es condición necesaria para nuestra comprensión de las obras de ficción. He sugerido, por último, que ese interés puede estar vinculado a la idea de narratividad.

\section{BIBLIOGRAFÍA}

Aristóteles, 2014, Ética a Nicómaco, trad. J. Pallí Bonet, Madrid, Gredos. Corbí, Josep E., 2012, Morality, Self-Knowledge and Human Suffering, Routledge, Nueva York.

Craig, Edward, 1999, Knowledge and the State of Nature: An Essay in Conceptual Synthesis, Oxford University Press, Oxford. 
Currie, Gregory, 2010, Narratives and Narrators: A Philosophy of Stories, Oxford University Press, Oxford.

- 1990 , The Nature of Fiction, Cambridge University Press, Cambridge.

Friend, Stacie, 2012, "Fiction as a Genre", Proceedings of the Aristotelian Society, vol. 112, no. 2, pp. 179-209.

- 2011, "Fictive Utterance and Imagining", Proceedings of the Aristotelian Society, vol. 85 sup., pp. 163-180.

—_, 2008, "Imagining Fact and Fiction", en Katheen Stock y Katherine Thomson-Jones (comps.), New Waves in Aesthetics, Palgrave, Basingstoke, pp. 150-169.

García-Carpintero, Manuel, 2016a, Relatar lo ocurrido como invención: una introducción a la filosofía de la ficción contemporánea, Cátedra, Madrid.

—_, 2016b, "To Tell What Happened as Invention: Literature and Philosophy on Learning from Fiction", en Andrea Selleri y Philip Gaydon (comps.), Literary Studies and the Philosophy of Literature: New Interdisciplinary Directions, Palgrave Macmillan, Londres, pp. 123-147.

— , 2013, "Norms of Fiction-Making", British Journal of Aesthetics, vol. 53, no. 3, pp. 339-357.

Ishiguro, Kazuo, 1989, The Remains of the Day, Faber and Faber, Londres.

- 1986, An Artist of the Floating World, Faber and Faber, Londres.

Kafka, Franz, 1972, "La condena”, La condena, trad. J.R. Wilcock, Alianza, Madrid, pp. 9-21.

Kant, Immanuel, 1996, Fundamentación de la metafísica de las costumbres, ed. y trad. José Mardomingo, Ariel, Barcelona.

Lewis, David, 1978, “Truth in Fiction”, American Philosophical Quarterly, vol. 15, no. 1, pp. 37-46.

Musil, Robert, 1995, The Man without Qualities, trad. Sophie Wilkins, Picador, Londres.

Nussbaum, Martha, 1992, Love's Knowledge: Essays on Philosophy and Literature, Oxford University Press, Oxford.

Peacocke, Christopher, 1987, "Depiction”, Philosophical Review, vol. 96, no. 3, pp. 383-410.

Stalnaker, Robert, 2002, "Common Ground", Linguistics and Philosophy, vol. 25, nos. 5-6, pp. 701-721.

Walton, Kendall, 1990, Mimesis and Make-Believe: On the Foundations of the Representational Arts, Harvard University Press, Cambridge, Mass.

Williams, Bernard, 2002, Truth and Truthfulness: An Essay in Genealogy, Princeton University Press, Princeton.

Williamson, Timothy, 1996, "Knowing and Asserting", Philosophical Review, vol. 105, no. 4, pp. 489-523.

Wollheim, Richard, 1980, Arts and Its Objects, Clarendon Press, Oxford.

Recibido el 4 de enero de 2017; revisado el 28 de marzo de 2017; aceptado el 7 de abril de 2017. 